semble diesel fuel ${ }^{12}$. Unfortunately, the named species does not grow in cooler climates. Calvin ${ }^{12}$ has suggested that the genes for biosynthesis of sesquiterpenes from Copaifera be transferred to species such as Euphorbia lathyris, a fuelproducing plant which can be grown in arid regions of the United States. Likewise, one might imagine that eukaryotic algae could be modified to produce more hydrogenase, and to bind $\mathrm{CO}_{2}$ less effectively at normal partial pressures. 1. O'Regan, B. \& Grätzel, M. Nature 353, 737-740
(1991).
2. Fujishima, A. \& Honda, K. Nature 238, 37-38 (1972).
3. Abrahams, I. L. et al. New J. Chem. 11, 157 (1987).
4. Gerischer, H. Photochem. Photobiol. 16, $243(1972)$.
5. Spitler, M. T. \& Calvin, M. J. chem. Phys. 66, 4294-
4305 (1977).
6. Spitler, M. T. \& Parkinson, B. A. Langmuir 2, 549-553
(1986).
7. Amadeli, R., Argazzi, R., Bignozzi, C. A. \& Scandola, F.
J. Am. chem. Soc. 112, 7099-7103 (1990).

\title{
Cold facts and naked truth
}

\section{Andrew R. Cossins}

THAT curious mammal, the naked mole rat, subject of a recent biography ${ }^{1}$, is even odder than it had seemed. Writing in the Journal of Thermal Biology ${ }^{2}$, Buffenstein and Yahav report that the animal is unable to regulate its body temperature and instead displays all the characteristics of a poikilotherm.

Not so long ago there were only two types of animal, warm-blooded (birds and mammals) and cold-blooded (the rest). This simple classification became confused by the discovery of warmblooded insects and reptiles, and of periodic hypothermia in small mammals ${ }^{3}$. Nevertheless, until now mammals and birds could still be characterized by their high resting metabolic rates, an effective surface insulation and high body temperatures in the cold.

The naked mole rat, Heterocephalus glaber, is found only in the tropical, semi-arid zones of north-east Africa, where it lives in a complex of poorly ventilated, subterranean burrows. Food is sparse and foraging through the burrow is an activity that dominates the energy budget. On the other hand, the burrows are thermally very stable at $28-32{ }^{\circ} \mathrm{C}$ but with a high humidity and the potential for low levels of oxygen and high levels of carbon dioxide ${ }^{4}$. The animals have a complex social structure. They live in subterranean colonies of 60-100 individuals, with a strict division of labour extending even to the provision of a single breeding female ${ }^{5}$. They often rest together in large huddles up to four animals deep.

The most notable features from a thermoregulatory point of view are a complete absence of fur and a poorly NATURE · VOL $353 \cdot 24$ OCTOBER 1991
In the light of the rapid progress made within the past five years in eukaryotic gene expression, and indeed in the engineering of entire metabolic pathways in prokaryotic organisms ${ }^{13}$, these seminatural alternatives to semiconductorbased solar cells could appear in the not so distant future.

Thomas E. Mallouk is in the Department of Chemistry and Biochemistry, University of Texas, Austin, Texas 78712, USA.

8. Roffia, S. et al. J. electroanal. Chem. 302, 157-171 (1991)

. Hashimoto, K., Hiramoto, M. \& Sakata, T. Chem. Phys. Lett. 148, 215,220 (1988)

10. Bolton, J. R. Strickler, S J. \& Connolly, J, S. Nature 315. 495-500 (1985)

11. Greenbaum, E. in Photochemical Energy Conversion (eds Norris, J. R. Jr \& Meisel, D.) 184-195 (Elsevier, New York, 1989).

12. Calvin, M. J chem. Ed. 64, 335-336 (1987).

13. Bailey, J. E. Science 252, 1668-1675 (1991).
The lesson here, however, is that the thermal conditions under which our present thermoregulatory taxonomy has been developed are irrelevant to these animals, because they never (or hardly ever) experience ambient temperatures below $28^{\circ} \mathrm{C}$ in their burrows ${ }^{4}$. So although they are technically poikilotherms ${ }^{7}$, their body temperature never falls below $28^{\circ} \mathrm{C}$.

The naked mole rat therefore provides an.exception to the rule that resting mammals have an effective system for endothermic thermoregulation. However, it is not simply a degenerate mammal in this respect, but has probably sacrificed a redundant physiology for some other adaptive benefit. It may be that reduced metabolic rates lower the possibility of overheating in an enclosed and humid burrow. Or perhaps the energetic savings on abandoning endothermy are crucial to balancing the energy budget in a food-scarce habitat.

Either way these animals offer new opportunities for the study of hypothermia in mammals because, unlike every other mammal, body temperature can be set at any desired level, at least in the short term, as it can in poikilotherms. This convenience may be also appreciated in studies of cold preservation of transplantation organs, where tissue may suffer from hypothermia in vivo. Experimental biology is littered with basal metabolic rate, were thought to restrict their thermoregulatory capacity and they were commonly regarded as poorly regulating homoeotherms 6 .

However, it is now clear that they also lack another fundamental attribute of the small homeothermic mammal, an effective mechanism for increasing the production of metabolic heat in the cold. One obvious manifestation of this property is an ability to elevate body temperature above a cool ambient temperature, but Buffenstein and Yahav show that the body temperature of the naked mole rat is only slightly $\left(0.5^{\circ} \mathrm{C}\right)$ above ambient over the range $12-37^{\circ} \mathrm{C}$. Another test of thermogenic potential is an animal's increased rate of oxygen consumption (and heat production) when transferred to the cold via the rapid activation of brown adipose tissue. Buffenstein and Yahav show that oxygen consumption is in fact greatly reduced in the cold.

This lack of thermogenic potential separates naked mole rats even from hibernating mammals of similar size, their production of metabolic heat being more than compensated for by high rates of evaporative and conductive cooling ${ }^{2}$.

\section{IMAGE UNAVAILABLE FOR COPYRIGHT REASONS}

examples of unusual creatures providing insight into fundamental biological processes. So, for the naked mole rat, opportunity knocks.

Andrew $R$. Cossins is in the Department of Environmental and Evolutionary Biology, University of Liverpool, PO Box 147, Liverpool L69 3BX, UK.

1. Sherman, P. W., Jarvis, J. \& Alexander, R. D. (eds) The Biology of the Naked Mole-Rat (Princeton University Press, 1991).

2. Buffenstein, R. \& Yahav, S. J. Thermal Biol. 16, $227-$ 232 (1991).

3. Cossins, A. R. \& Bowler, K. Temperature Biology of Animals (Chapman \& Hall, London, 1987)

4. Bennet, N. B. et al. S. Afr. J. Zool. 3, 189-195 (1988)

5. Jarvis, J. U. M. Science 212, 571-573 (1981).

6. Withers, P. C. \& Jarvis, J. U. M. Comp. Biochem. Physiol 66A, 215-219 (1980).

IUPS Thermal Commission Pflügers Arch. ges. Physiol. 410, 567-587 (1987). 